\title{
Study of physico-chemical composition of red delicious and amri apple varieties under fresh and stored condition
}

\author{
Zakia Bibi ${ }^{1}$, Fazal Muhammad Bangulzai ${ }^{*}$, Nazeer Ahmed ${ }^{1}$, Abdul \\ Raziq $^{1}$, Syed Muhammad Ishaq ${ }^{1}$, Shah Faisal ${ }^{1}$, Lal Bakhsh ${ }^{2}$ and Abdul \\ Qadir $^{3}$ \\ 1. Agriculture Research Institute (A.R.I) Sariab Quetta, Balochistan-Pakistan \\ 2. Directorate of Agriculture Research, Usta Muhammad Balochistan-Pakistan \\ 3. Horticulture Research Institute BARDC (PARC) Khuzdar-Pakistan \\ *Corresponding author's email: fazalbangulzai786@gmail.com
}

Citation

Zakia Bibi, Fazal Muhammad Bangulzai, Nazeer Ahmed, Abdul Raziq, Syed Muhammad Ishaq, Shah Faisal, Lal Bakhsh and Abdul Qadir. Study of physico-chemical composition of red delicious and amri apple varieties under fresh and stored condition. Pure and Applied Biology. Vol. 8, Issue 1, pp58-67. http://dx.doi.org/10.19045/bspab.2018.700164

\begin{tabular}{llll}
\hline \hline Received: 07/08/2018 & Revised: 02/10/2018 & Accepted: 04/10/2018 & Online First: 10/10/2018 \\
\hline \hline
\end{tabular}

\section{Abstracts}

A laboratory Experiment was carried out to determine the physic-chemical composition of Red Delicious and Amri apple varieties under fresh and stored condition, which were determined on October 30, November 30, and December 30. The physical and chemical characteristics determined were, fruit length and diameter, single fruit weight, juice percentage, total soluble solids (TSS), acidity percentage, ascorbic acid, reducing and non-reducing sugar percentage. It is obvious from the results that the varieties had significant differences for fruit length, fruit diameter and single fruit weight. Juice percentage remained unaffected due to varieties. Variety Red Delicious was considered to be better in physical properties when its comparison was made with variety Amri. Observation intervals had significant effect on fruit length and juice percentage, while fruit diameter and single fruit weight remained unaffected. The result mean interval of Red Delicious observations TSS \% (14.29), Acidity \% (0.42), Ascorbic acid (5.61), Reducing sugar \% (7.08) and Non-reducing sugar \% (2.54) was obtained as compare to variety Amri the result mean interval TSS \% (14.21), Acidity \% (0.36), Ascorbic acid (4.43Mg), Reducing sugar \% (6.81) and Non-reducing sugar \% (4.08) was obtained. The result illustrated that for chemical analysis varieties had significant effect on acidity percentage, ascorbic acid and non-reducing sugars, while T.S.S and reducing sugars remained unaffected due to different varieties. All the chemical properties i.e. T.S.S, acidity, ascorbic acid, reducing sugars and non-reducing sugars affected significantly by observation intervals.

Keywords: Apple varieties; Fresh Physico-chemical composition; Storedcondition

\section{Introduction}

The apple belongs to the family "Rosaceae" and the sub-family Pomoideae. Other subfamilies members are pear and quince .The botanical name (s) of apple are used inconsistently. Some reported names are pyrus malus L, Malus sulvestris, and Malus malus. The genus pyrus is further subdivided 
in to two sub-genera, Malus is the sub genesis are united at the base, the calyx's tube is open, the flowers are colored, and the fruit globular, the flowers is perfect with 5 sepals, 5petals, 5 carpals with 2 ovules each, and 1520 stamens. The tree is up right spreading, deciduous, and carries mixed buds which produce flower and mostly spur - bearing leaves. Apple is one of the leading fruit amongst all the fruits grown in the temperate regions. The apple tree is one of the most adaptable of plants. The main garden types are dwarf and semi-dwarf, bushes and cordons. There are also various ornamentals forms. Apples are budded (grafted) on to specially developed root stocks. The root stocks resemble the original species of Malus from which most apple trees are derived. They are usually denoted by numbers and letters which refer to the research station where they were developed [1].

The apple is one of the most important fruits of the world. In Pakistan its cultivation is limited and is restricted to the northern hilly tracts of Punjab and KPK, and the Quetta region of Baluchistan. Apple is of high nutritive values and edible fruit contains $88 \%$ moisture, $0.04 \%$ protein, $0.2 \%$ ash, iron 0.8 $\mathrm{ug} / 100 \mathrm{~g}$, iodine $0.08 \mathrm{ug} / 100 \mathrm{~g}$ and phosphorus $10.2 \mathrm{mg} / 100 \mathrm{gm}$.

Apple is not only the delicious, but also highly nutritive fruit crop of temperate region in the world. It is a leading crop of geographical areas lying between the latitude of $30^{\circ}$ to $35^{\circ}$ in the globe.

Some 5000 - 6000 varieties of apples are described in literature; however, only a few are important for any particular region. To select a variety, important characteristics are studied under local conditions. A selected variety should: an annual bearer, good to very good in taste quality, attractive in appearance, relatively paste-resistant, productive, and hardy. Good storage and handling quality further increase the value of the variety. Some important varieties grown in various apple-growing regions of Pakistan are: the Quetta region. Kashmiri, kandhari, Amri and Qalat special [2].

In the list of all the temperate fruits, apple is regarded as one of the best fruit in possession of long keeping quality. Under local condition, a limited research work is done on apple, hence in view of the biological importance of apple, it was considered necessary to study physic-chemical composition of Red delicious and Amri apple varieties under fresh and stored conditions.

\section{Materials and methods}

A laboratory experiment was carried out to study physic-chemical composition of Red Delicious and Amri apple varieties under fresh and stored condition during 2007-2009, at Agriculture College Balali, Quetta and Agriculture Research Institute, Quetta. The apple fruits of specified varieties were purchased from the local market of Quetta at different intervals to analyze the physical as well as chemical properties, which were determined on October 30, November 30, and December 30.

Physical and chemical properties of apple were analyzed as per the methods described here under:

\section{A. Physical composition}

Physical composition was determined on the basis of 10 randomly selected fruit samples to evaluate the following characters, Fruit length $(\mathrm{cm})$, Diameter of fruit $(\mathrm{cm})$ and Single fruit weight $(\mathrm{g})$.

\section{B. Chemical composition}

\section{TSS}

Total soluble solids were determined by means of refrectometer at room temperature, using method 22.3 as recommended by A.O.A.C. [3]. Moisture content was determined by using A.O.A.C (1970) method 16-20, using hot air oven.

\section{Acidity}

Acidity was determined by the 20-31 method as suggested by A.O.A.C. (1970).

Ascorbic acid in $100 \mathrm{ml}$ of juice (mg) 
Ascorbic acid was determined by A.O.A.C. [3] method 40-45 using 2-6 Dichlorophenol indophenols as a dye.

\section{Reducing Sugar Percentage}

Reducing sugar was determined by Lan Eynon method 29-36 described by A.O.A.C. [3].

\section{Non-Reducing Sugar Percentage}

Non -reducing sugar was analyzed by Lan Eynon method 29-36 described [3] by A.O.A.C. (1970). The determinations for all the physical and chemical character were replicated three times, and the data so obtained were subjected to analysis of variance using Randomized Complete Block Design with Factorial arrangements. The superiority of treatment means was observed by using L.S.D. (Least Significant Different) test, following [4] Gomes and Gomez (1984) and within treatment groups variation was done by D.M.R .Test .All these tests were applied / computed through MSTAT-C Computer software.

\section{Juice Percentage}

Juice was extracted by the electric juice extractor Japan made and percentage was calculated on weight basis.

\section{Results and discussion}

A laboratory experiment carried out to study the physic-chemical composition of Red Delicious and Amri apple varieties under fresh and stored condition during 2007-2009, which were determined on October 30, November 30. And December 30.the physical and chemical characteristics determined were, juice percentage, total soluble solids, (TSS), acidity percentage, ascorbic acid, reducing and non- reducing sugar percentage. The data is recorded in table 1 to 9 and their analysis of variance as of variance as Appendices I to IX. The result is discussed in detail as follows;

\section{Physical properties Length of Fruit}

The data for apple varieties as affected by different time interval is presented in Table-
1.The data and the statistical analysis illustrated that the difference in fruit length of different varieties and intervals were significant $(\mathrm{P} \leq 0.01)$, while non-significant for interaction between varieties and intervals.

It is obvious from the results (Table 1) that apple variety Red Delicious produced fruits of greater length $(5.93) \mathrm{cm}$, as compared to Amri, $(5.69 \mathrm{~cm})$. In case of interval, fruit analyzed on December 30, produced comparatively greater length $(6.04 \mathrm{~cm})$ than the fruits analyzes on November $30(5.78 \mathrm{~cm}$ ) or October $30(5,61 \mathrm{~cm})$. The result further revealed that interaction between variety Red Delicious x December 30 date of observation produced comparatively greater fruit length $(6.12 \mathrm{~cm})$, followed by interaction of variety Amri X December 30 and variety Red Delicious X November 30 observational dates with mean fruit length of 5.96 and 5.89 $\mathrm{cm}$ is descending order. However, the differences were statistically non-significant. The results reported by Ginai [5] had also the similarity with the present findings. The coefficient of variation per fruit sample recorded was 3.40 percent.

\section{Diameter of fruit}

The result pertaining to fruit diameter of two apple varieties as affected by different time intervals are recorded in Table-2.The results and the analysis of variance revealed that $e$ differences in fruit diameter were significant $(\mathrm{P} \leq 0.05)$ FOR varieties, while nonsignificant for time intervals and interaction between varieties and intervals. It can be observed from the results (Table 2) that apple variety Red Delicious produced fruits of greater diameter $(6.64 \mathrm{~cm})$, as compared to Amri $(6.08 \mathrm{~cm})$.In case Of Intervals Fruit Analyzed on December $30^{\text {th }}$, produced comparatively greater diameter $(6.58 \mathrm{~cm})$ than the fruits analyzed on November $30^{\text {th }}$ $(6.37 \mathrm{~cm})$ or October $30^{\text {th }}(6.13 \mathrm{~cm})$. The results further revealed that interaction between variety Red Delicious X December 
$30^{\text {th }}$ date of observation produced comparatively greater fruit diameter $(6.90 \mathrm{~cm})$, followed by interaction of variety Red Delicious X November 30 and variety Red Delicious X October 30 observation dates, with mean fruit diameter of 6.65 and $6.35 \mathrm{~cm}$ respectively. How, ever the difference were statistically non-significant for treatment interaction. The coefficient of variation per fruit sample was 7.66 percent.

Table 1. Mean length of apple fruit $(\mathrm{cm})$ of different varieties as affected by time intervals

\begin{tabular}{|c|c|c|c|}
\hline Interval & \multicolumn{2}{|c|}{ Varieties } & \multirow{2}{*}{ Mean for Varieties } \\
\hline $30^{\text {th }}$ October & 5.78 & Amri & 5.61 \\
\hline $30^{\text {th }}$ November & 5.89 & 5.44 & 5.78 \\
\hline $30^{\text {th }}$ December & 6.12 & 5.68 & 6.04 \\
\hline Mean for interval & $5.93 \mathrm{ab}$ & 5.96 & 5.81 \\
\hline \multicolumn{2}{|c|}{ Varieties (v) } & $5.69 \mathrm{ab}$ & V X I \\
\hline S.E & 0.0807 & Interval (I) & 0.0571 \\
\hline LSD 0.05 & 0.2882 & 0.0699 & ------- \\
\hline LSD 0.01 & 0.3906 & 0.3043 & ------ \\
\hline CV\% & $3.40 \%$ & 0.4265 & \\
\hline
\end{tabular}

Table 2. Mean diameters of apple fruit $(\mathrm{cm})$ of different varieties as affected by time intervals

\begin{tabular}{|c|c|c|c|}
\hline \multirow[t]{2}{*}{ Interval } & \multicolumn{2}{|c|}{ Varieties } & \multirow{2}{*}{ Mean Varieties } \\
\hline & Red Delicious & Amri & \\
\hline $30^{\text {th }}$ October & 6.35 & 5.91 & 6.13 \\
\hline $30^{\text {th }}$ November & 6.65 & 6.08 & 6.37 \\
\hline $30^{\text {th }}$ December & 6.90 & 6.25 & 6.58 \\
\hline Mean for intervals & $6.64 \mathrm{a}$ & $6.08 \mathrm{~b}$ & 6.36 \\
\hline \multicolumn{2}{|c|}{ Varieties (v) } & Interval (I) & V X I \\
\hline S.E & 0.1968 & 0.1722 & 0.1406 \\
\hline LSD 0.05 & 0.0750 & ------- & ------- \\
\hline LSD 0.01 & ------- & ------- & ------- \\
\hline $\mathrm{CV} \%$ & 7.66 & & \\
\hline
\end{tabular}

\section{Weight of single fruit}

The results pertaining to wait of single fruit of red delicious and Amri apple varieties as affected by different time interval recorded in (Table 3). The analyses as variance revealed that the weight of single apple fruit varied significantly $(\mathrm{P}<0.01)$.In case of different varieties, but non-significant differences were observed for time intervals and interaction between varieties and intervals. The result presented in Table-3, exhibit that apple variety Red Delicious produced fruits of significantly higher weight $(145.67 \mathrm{~g})$, as compared to Amri (112.42 g) . In case of intervals, apples analyzed on November 30, had comparatively single fruit weight (14.63 g) then the fruit analyzed on December30 or October 30 having single fruit weight of $127.50 \mathrm{~g}$ and $125.00 \mathrm{~g}$ respectively. The results further revealed the interaction between variety Red Delicious X November 30 date of observation produced comparatively greater single fruit weight $(153.00 \mathrm{~g})$,followed by interaction of variety Red Delicious X December 30 and variety Rd Delicious X October 30 observation dates, with mean single fruit weight of $145.00 \mathrm{~g}$ and $139.00 \mathrm{~g}$ respectively. However, the differences were statistically non-significant for treatment interaction.These results are 
further supported by Chattopadhyay et al. [6] and Hallad et al. [7] who also observed different fruit weight in different varieties.
The co efficient of variation per fruit sample was 7.07 percent.

Table 3. Mean single fruit weight (g) of different varieties as affected by time intervals

\begin{tabular}{|c|c|c|c|}
\hline \multirow[t]{2}{*}{ Intervals } & \multicolumn{2}{|c|}{ Varieties } & \multirow{2}{*}{ Mean for varieties } \\
\hline & Red Delicious & Amri & \\
\hline $30^{\text {th }}$ October & 139.00 & 111.00 & 125.00 \\
\hline $30^{\text {th }}$ November & 153.00 & 116.25 & 134.63 \\
\hline $30^{\text {th }}$ December & 145.00 & 110.00 & 127.50 \\
\hline Mean fir intervals & 145.67 & 112.42 & 129.04 \\
\hline \multicolumn{2}{|c|}{ Varieties (v) } & Interval (I) & VX I \\
\hline S.E & 3.7257 & 3.2266 & 2.6345 \\
\hline LSD 0.05 & 13.320 & ------- & ------- \\
\hline LSD 0.01 & 18.050 & ------- & -------- \\
\hline $\mathrm{CV} \%$ & 7.07 & & \\
\hline
\end{tabular}

\section{Juice percentage}

Juice percentage in apple fruit is of great importance. The result in connection with juice percentage of two varieties as affected by different time intervals are produced in (Table 4). The data and the analysis of variance envisaged that the differences in juice percentage were significant for time intervals $(\mathrm{P}<0.05)$ and interaction between varieties and intervals $(\mathrm{P}<0.05)$, while nonsignificant for different varieties.It can be seen from the result (Table 4), that apple variety Red Delicious and Amri has almost similar juice percentage higher juice percentage was recorded when they analyzes on November 30 ,followed by October 30 with juice percentage of 70.00 percent, while the minimum juice percentage of 68.28 percent was recorded when apple fruit were analyzed on December 30. The results for treatment interaction reveal that interaction between variety Amri X November 30 date of observation produced significantly greater fruit juice percentage $(71.61 \%)$ followed by interaction of variety Red Delicious $\mathrm{X}$ October 30 and variety Amri October 30 observation dates, with mean juice percentage of $71.33 \%$ and $70.66 \%$ respectively.These results are further supportedby Chattopadhyay et al.[6]and Hallad et al.[7]. The coefficient of variation per fruit sample for this parameter was 2.41 $\%$.

Table 4. Mean juice percentage in fruit $(\%)$ of different varieties as affected by time intervals

\begin{tabular}{|c|c|c|c|}
\hline \multirow[t]{2}{*}{ Intervals } & \multicolumn{2}{|c|}{ Varieties } & \multirow[t]{2}{*}{ Mean of Varieties } \\
\hline & Red Delicious & Amri & \\
\hline $30^{\text {th }}$ October & 71.33 & 68.66 & 70.00 \\
\hline $30^{\text {th }}$ November & 70.66 & 71.61 & 71.14 \\
\hline $30^{\text {th }}$ December & 67.33 & 69.22 & 68.28 \\
\hline Mean for intervals & 69.77 & 69.83 & 69.80 \\
\hline \multicolumn{2}{|c|}{ Varieties (v) } & Interval (I) & VX I \\
\hline S.E & 0.6865 & 0.5946 & 0.4855 \\
\hline LSD 0.05 & ------- & 2.4540 & 2.9100 \\
\hline LSD 0.01 & ------- & ------- & -------- \\
\hline $\mathrm{CV} \%$ & 2.41 & & \\
\hline
\end{tabular}




\section{Chemical properties}

\section{Total soluble solids}

The data for total soluble solids in fruit juice of two Apple varieties, examined on various dates are presented in Table -5 . The analysis of variance results described that the differences for total soluble solids were statistically significant $(\mathrm{P}<0.05)$ for intervals and non- significant for varieties and interaction between varieties and intervals. The results in (Table 5) illustrated that comparatively greater total soluble solids were recorded in Red Delicious (14.29\%) than variety Amri had $14.21 \%$ total soluble solids on average. In case of intervals, the total soluble solids were significantly higher ( 15.63) when fruit analyzed on December 30, closely followed by $16.16 \%$ T.S.S under
November 30, observation and minimum T.S.S , of $12.98 \%$ when apple were analyzed on October 30. The result for treatment interval reveals that variety Amri $X$ December 30 and Red Delicious X December 30 , interaction had comparatively greater T.S.S 15.90 and $15.34 \%$, while minimum T.S.S $12.87 \%$ recorded under treatment interaction of variety Red Delicious X October 30 observation date. It was deduced that after picking of apple fruit the total soluble solids are increased with each delay in consumption and moisture percentage is reduced. These results are further supported by Pal and Kumar [8] and Yuen et al. [9]. The coefficient of variation per fruit sample for this character was $11.19 \%$.

Table 5. Mean T.S.S $(\%)$ in apple fruit juice of different varieties as affected by time intervals

\begin{tabular}{|c|c|c|c|}
\hline \multirow[t]{2}{*}{ Intervals } & \multicolumn{2}{|c|}{ Varieties } & \multirow{2}{*}{ Mean of Varieties } \\
\hline & Red Delicious & Amri & \\
\hline $30^{\text {th }}$ October & 12.87 & 13.08 & 12.98 \\
\hline $30^{\text {th }}$ November & 14.66 & 13.66 & 14.16 \\
\hline $30^{\text {th }}$ December & 15.35 & 15.90 & 15.63 \\
\hline Mean for intervals & 14.29 & 14.21 & 14.25 \\
\hline \multicolumn{2}{|c|}{ Varieties (v) } & Interval (I) & V X I \\
\hline S.E & 0.6514 & 0.5641 & 0.4606 \\
\hline LSD 0.05 & ------- & 2.3290 & ------- \\
\hline LSD 0.01 & ------- & ------- & $\begin{array}{l}------- \\
\end{array}$ \\
\hline $\mathrm{CV} \%$ & 11.19 & & \\
\hline
\end{tabular}

\section{Acidity percentage}

Determination of acidity level in Apple is an important aspect. The data for acidity percentage in apple fruit of two varieties, examined on different dates are presented in (Table 6). The analysis of variance leads to state that the differences for acidity percentage were significant $(\mathrm{P}<0.01)$ for varieties and intervals but non-significant for interaction between varieties and intervals. Theresults presented in Table -6 , reveal that acidity percentage was maximum in variety Red Delicious ( $0.42 \%$ ) followed by Amri with mean acidity of $0.36 \%$. The higher acidity percentage in Red Delicious variety might be due to the genetically behavior of its parental material. So for the intervals are concerned, fruits determined on October 30 had the maximum acidity percentage of $0.44 \%$, followed by November 30 observation, where acidity was 0.39 percent and minimum acidity level of 0.35 percent was recorded when fruit were analyzed on December 30. The results for treatment interval reveal that variety Red Delicious X October 30 had the maximum $(0.48 \%)$ acidity percentage. followed by treatment interaction of variety Red Delicious X October 30 observation date, while the minimum acidity percentage of 0.33 percent 
as recorded under treatment interaction of variety Amri X December 30,observation date. These results are further supported by
Barwel [10]. The coefficient of variation per fruit sample for this character was 9.48 percent.

Table 6. Mean acidity (\%) in apple fruit juice of different varieties as affected by time intervals

\begin{tabular}{|c|c|c|c|}
\hline \multirow[t]{2}{*}{ Intervals } & \multicolumn{2}{|c|}{ Varieties } & \multirow{2}{*}{ Mean for Intervals } \\
\hline & Red Delicious & Amri & \\
\hline $30^{\text {th }}$ October & 0.48 & 0.40 & 0.44 \\
\hline $30^{\text {th }}$ November & 0.43 & 0.35 & 0.39 \\
\hline $30^{\text {th }}$ December & 0.36 & 0.33 & 0.35 \\
\hline Mean for intervals & 0.42 & 0.36 & 0.39 \\
\hline \multicolumn{2}{|c|}{ Varieties (v) } & Interval (I) & VX I \\
\hline S.E & 0.0152 & 0.0131 & 0.0107 \\
\hline LSD 0.05 & 0.0462 & 0.0683 & ------- \\
\hline LSD 0.01 & 0.0625 & 0.0683 & -------- \\
\hline CV\% & 9.48 & & \\
\hline
\end{tabular}

\section{Ascorbic acid}

Ascorbic acid is one of the valuable constituents in fruits. The data pertaining to ascorbic acid content in apple fruit of two varieties, determined on different dates are recorded in (Table 7). The analysis of variance illustrated that the difference for ascorbic acid content were significant $(\mathrm{P}>$ 0.01) for varieties and intervals while nonsignificant for interaction between varieties and intervals. The results in Table-7,revealed that ascorbic acid was maximum in variety Red Delicious ( $5.61 \mathrm{mg} / 100 \mathrm{ml}$ juice) followed by variety Amri with mean ascorbic acid of $4.43 \mathrm{mg} / 100 \mathrm{mi}$ juice . So far, the intervals are concerned, fruits determined on October 30 had greater ascorbic acid $6.48 \mathrm{mg}$ / 100 juice followed by November 30 and December 30 observation, where ascorbic acid recorded was 5.04 and $3.55 \mathrm{mg} / 100 \mathrm{ml}$ juice respectively. The results for treatment interaction reveals that ascorbic acid was comparatively greater $6.85 \mathrm{mg} / 100 \mathrm{ml}$ juice in case of variety Red Delicious X October 30 , closely followed by $6.10 \mathrm{mg} / 100 \mathrm{ml}$ juice under treatment interaction of variety Amri October 30 observation date, while, the minimum ascorbic acid 3mg / $100 \mathrm{ml}$ juice was noticed in interaction of variety Amri X
December 30 observation date. Similarly, the differences were non-significant statistically. These results are further supported by Barwel[10]. The coefficient of variation per fruit sample for this character was 9.96 percent.

\section{Reducing sugar}

The results reducing sugar content in apple fruit of two varieties, evaluated on different dates are recorded in (Table 8). The data and analysis of variance demonstrated that the difference for reducing sugar content were significant $(\mathrm{P}<0.01)$ for intervals and treatment interaction between varieties and intervals, while non-significant for varieties. It is obvious from the results that reducing sugar content was maximum in variety Red Delicious $7.08 \%$, followed by variety Amri with mean reducing sugar content of 6.81 percent. In case of intervals, fruits analyzed on December 30 had greater reducing sugar content $9.02 \%$ followed by November 30 and October determination, where reducing sugar level was 6.76 and $5.06 \%$, respectively. The interaction study revealed that variety Red Delicious when determined on December 30 and had greater reducing sugar level of $10.10 \%$ while interaction between varieties Amri X December 30 
ranked second with reducing sugar content of $7.93 \%$. The minimum reducing sugar content was recorded in treatment interaction of variety Red Delicious October 30 observation date.These results are further supported by Halladet al. [7] and Barwel [10].The coefficient of variation per fruit sample for this character was $9.60 \%$.

Table 7. Mean ascorbic acid percentage in juice (\%) of different apple varieties as affected by time intervals

\begin{tabular}{|c|c|c|c|}
\hline \multirow[t]{2}{*}{ Intervals } & \multicolumn{2}{|c|}{ Varieties } & \multirow{2}{*}{ Mean for Varieties } \\
\hline & Red Delicious & Amri & \\
\hline $30^{\text {th }}$ October & 6.85 & 6.10 & 6.48 \\
\hline $30^{\text {th }}$ November & 5.89 & 4.20 & 5.04 \\
\hline $30^{\text {th }}$ December & 4.10 & 3.00 & 3.55 \\
\hline Mean for intervals & 5.61 & 4.43 & 5.02 \\
\hline \multicolumn{2}{|c|}{ Varieties (v) } & Interval (I) & V X I \\
\hline S.E & 0.2043 & 0.1769 & 0.144 \\
\hline LSD 0.05 & 0.7703 & 0.7297 & ------- \\
\hline LSD 0.01 & 1.0800 & 0.9889 & $\begin{array}{ll}-------- \\
\end{array}$ \\
\hline CV\% & 9.96 & & \\
\hline
\end{tabular}

Table 8. Mean reducing sugar content in juice (\%) of different apple varieties as affected by time intervals

\begin{tabular}{|c|c|c|c|}
\hline \multirow[t]{2}{*}{ Intervals } & \multicolumn{2}{|c|}{ Varieties } & \multirow{2}{*}{ Mean for Varieties } \\
\hline & Red Delicious & Amri & \\
\hline $30^{\text {th }}$ October & 4.21 & 5.91 & 5.06 \\
\hline $30^{\text {th }}$ November & 6.92 & 6.60 & 6.76 \\
\hline $30^{\text {th }}$ December & 10.10 & 7.93 & 9.01 \\
\hline Mean for intervals & 7.08 & 6.81 & 6.94 \\
\hline \multicolumn{2}{|c|}{ Varieties (v) } & Interval (I) & V X I \\
\hline S.E & 0.2722 & 0.2357 & 0.1925 \\
\hline LSD 0.05 & ------- & 0.9724 & 1.1530 \\
\hline LSD 0.01 & 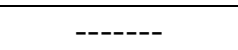 & 1.3180 & 1.7470 \\
\hline CV\% & 9.60 & & \\
\hline
\end{tabular}

\section{Non-reducing sugar}

The data pertaining to non-reducing sugar content in apple fruit of two varieties, evaluated on different dates are presented in (Table 9). The analysis of variance described that the differences for non-reducing sugar content were highly significant $(\mathrm{P}<0.01)$ for varieties, intervals as well as for interaction between varieties and intervals. The results show that non -reducing sugar content was the highest in variety Amri $4.08 \%$, followed by variety Red Delicious with mean nonreducing sugar content of $2.54 \%$. In case of intervals, fruits determined on October 30 had greater non-reducing sugar content 5.00 $\%$ followed by November 30 and December determination, where non-reducing sugar level 3.30 and $1.63 \%$, respectively. The result further revealed that interaction between varieties Amri X October 30, had the maximum non-reducing sugar level (6.00), and followed by treatment interaction of variety Amri X November 30 and variety Red Delicious X October 30 ranked second and third in non- reducing sugar level 4.10 and $4.00 \%$ respectively. These results are further supported by Hallad et al. [7] and Barwel [10]. The coefficient of variation per 
fruit sample for this character was 0.49 percent.

A laboratory Experiment was carried out to determine the physic-chemical composition of Red Delicious and Amri apple varieties under fresh and stored condition during 2007-2009 which were determined on
October 30, November 30, and December 30. The physical and chemical characteristics determined were; fruit length and diameter, single fruit weight, juice percentage, total soluble solids (TSS), acidity percentage, ascorbic acid, reducing and non-reducing sugar percentage.

Table 9. Mean non-reducing sugar content in juice (\%) of different apple varieties as affected by time intervals

\begin{tabular}{|c|c|c|c|}
\hline \multirow[t]{2}{*}{ Intervals } & \multicolumn{2}{|c|}{ Varieties } & \multirow{2}{*}{ Mean for Varieties } \\
\hline & Red Delicious & Amri & \\
\hline $30^{\text {th }}$ October & 4.00 & 6.00 & 5.00 \\
\hline $30^{\text {th }}$ November & 2.50 & 4.10 & 3.30 \\
\hline $30^{\text {th }}$ December & 1.11 & 2.15 & 1.63 \\
\hline Mean for intervals & 2.54 & 4.08 & 3.31 \\
\hline \multicolumn{2}{|c|}{ Varieties (v) } & Interval (I) & V X I \\
\hline S.E & 0.00670 & 0.00580 & 0.1925 \\
\hline LSD 0.05 & 0.01459 & 0.01541 & 0.05471 \\
\hline LSD 0.01 & 0.01978 & 0.02150 & 0.08290 \\
\hline CV\% & 0.49 & & \\
\hline
\end{tabular}

The determinations for all the physical and chemical characters were replicated three times, and the data so obtained were subjected to analysis of variance using Randomized complete Design with Factorial arrangement. The superiority of treatment means was observed by using L.S.D test. D.M /R test as also applied to compare the treatment mean.

The finding of the study is summarized as follows:

\section{Analysis of physical properties}

It is obvious from the results that the varieties had significant differences for fruit length, fruit diameter and single fruit weight. Juice percentage remained unaffected due to varieties. Variety Red Delicious was considered to be better in physical properties when its comparison was made with variety
Amri. Observation intervals had significant effect on fruit length and juice percentage, while fruit diameter and single fruit weight remained unaffected.

\section{Analysis of chemical properties}

The result illustrated that for chemical analysis varieties had significant effect on acidity percentage, ascorbic acid and nonreducing sugars, while T.S.S and reducing sugars remained UN affected due to different varieties. All the chemical properties i.e. T.S.S, acidity, ascorbic acid, reducing sugars and non-reducing sugars affected significantly by observation intervals.

The chemical properties of different varieties are summarized in (Table 10).

Mean chemical composition as affected by the intervals are summarized (Table 11).as follows:

Table 10. Chemical properties of Red delicious and Amri

\begin{tabular}{|c|c|c|}
\hline \multicolumn{2}{|c|}{ Red Delicious } & Amri \\
\hline TSS \% & 14.29 & 14.21 \\
\hline Acidity \% & 42 & 0.36 \\
\hline Ascorbic acid & 5.61 & $4.43 \mathrm{Mg} / 100 \mathrm{ml}$ juice \\
\hline Reducing sugar \% & 7.08 & 6.81 \\
\hline Non-reducing sugar \% & 2.54 & 4.08 \\
\hline
\end{tabular}


Table 11. Mean chemical composition as affected by the intervals

\begin{tabular}{|c|c|c|c|}
\hline \multicolumn{2}{|c|}{ Oct, 30 } & Nov, 30 & Dec, 30 \\
\hline TSS \% & 12.98 & 14.16 & 15.63 \\
\hline Acidity \% & 0.44 & 0.39 & 0.35 \\
\hline Ascorbic acid & 6.48 & 5.05 & $3.55 \mathrm{Mg} / 100 \mathrm{ml}$ juice \\
\hline Reducing sugar \% & 5.06 & 6.76 & 9.01 \\
\hline Non-reducing sugar \% & 5.00 & 3.30 & 1.63 \\
\hline
\end{tabular}

The interaction between varieties and intervals had significant effect only on juice percentage among physical properties and reducing sugar and non-reducing percentage among the chemical properties. Remaining all the physical and chemical characters remained unaffected by treatment interaction.

\section{Conclusions}

From the present study it was concluded that apple variety Red Delicious had better physical and chemical properties as compared to Amri. In some cases variety had been at par with the Red Delicious, but not in single physical or chemical properties it could show better performance as compared to variety Red Delicious. Though Amri is good variety and is liked generally, but when compared with Red Delicious, it could not show comparative better results.

\section{Authors' contributions}

Conceived and designed the experiments: $\mathrm{Z}$ Bibi \& FM Bangulzai, Performed the experiments: Z Bibi \& FM Bangulzai, Analyzed the data: $N$ Ahmed, Contributed reagents/materials/analysis tools: $\mathrm{N}$ Ahmed, L Bakhsh, A Raziq \& S M Ishaq, Wrote the paper: FM Bangulzai \& Z Bibi.

\section{References}

1. Hall MT (1978).Successful Fruit and Vegetable. Orbis Pub Ltd Landon pp 9-10.

2. Mahmood NM (2009). Hort 1st Edipp468.
3. AOAC (1970). Official methods of analysis. Associ of office Analychem $11^{\text {th }}$ Ed Wash DC.

4. Gomez KA \& Gomez (1984). Sta for Agric Res (11nd Edi), John Willey \& Sons. New York.

5. Gini A (1995). Quetta Apples. West Pakistan. J Agric Res 3:118-121.

6. Chattopadhyay PK, Mandal A \& Mandal A (1993). Physico-chemical characteristics of clustered apple as influenced by N, P \& K nutrition. J of Trop Agric 31(2): 237-238.

7. Hallad JS, Sulikeri GS \& Hulamani NC (1993).Physico-chemical properties of cashew (Anacardium Occidentale L.) apples of different cultivars. Cashew 7(1): 10-11.

8. Pal DK \& Kumar PS (1995). Changes in the physico-chemical and biochemical composition of custard apple (Annona squamosal L) fruits during growth, development and Ripening. $J$ of Hort Sci 70(4): 569-572.

9. Yuen CMC, Haynes Y \& Warton (1995).Consumer acceptance of Jonathan and Delicious Apples in relation to fruit Maturity and physic- chemical attributes. ASEAN Fd J 10(4): 139-144.

10. Barwel VS (1995). Maturity index studies of new strains of apple. $H J$ of Agric-Res 21(1-2): 60-64. 